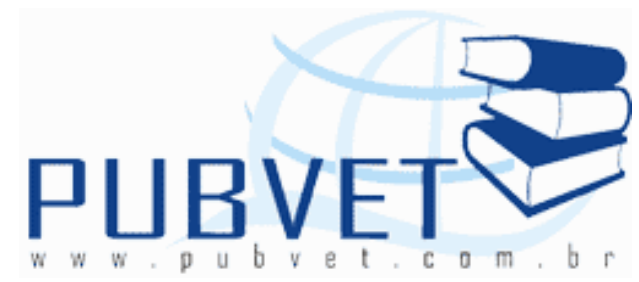

PUBVET, Publicações em Medicina Veterinária e Zootecnia.

\title{
Algumas considerações sobre as exigências nutricionais das gramíneas forrageiras tropicais
}

\section{Guilherme de Lira Sobral Silva ${ }^{1}$, Maria Socorro de Souza Carneiro², Magno José Duarte Cândido ${ }^{2}$, Francisca Mirlanda Vasconcelos Furtado ${ }^{3}$, Francisco José de Seixas Santos ${ }^{4}$, Maykon Sousa da Silva ${ }^{5}$, Newton de Lucena Costa ${ }^{6}$, João Avelar Magalhães ${ }^{7}$}

${ }^{1}$ Méd. Vet., D.Sc., Pós-Doutorando em Zootecnia, UFC, Fortaleza, Ceará.

${ }^{2}$ Eng. Agr., D.Sc., Professor(a) do Curso de Doutorado em Zootecnia da UFC, Fortaleza, Ceará.

${ }^{3}$ Zootecnista, M.Sc., Doutorando em Zootecnia, UFC, Fortaleza, Ceará. ${ }^{4}$ Eng. Agr., D.Sc., Pesquisador da Embrapa Meio-Norte, Parnaíba, Piauí. ${ }^{5}$ Eng. Agr., B.Sc., Mestrando em Agronomia UFC, Fortaleza, Ceará. ${ }^{6}$ Eng. Agr., D.Sc., Pesquisador da Embrapa Roraima, Boa Vista, Roraima. ${ }^{7}$ Méd. Vet., D.Sc., Pesquisador da Embrapa Meio-Norte, Parnaíba, Piauí.

\section{Resumo}

Ao longo dos anos têm-se estudado os solos, as plantas forrageiras e a nutrição dos ruminantes separadamente. Entretanto o sistema solo-plantaanimal é complexo e interdependente, o que pode levar ao insucesso do sistema produtivo quando a inclusão da forrageira é inadequada. Quando se pensa em implantação ou persistência das pastagens cultivadas um dos principais fatores a levar em consideração, é o adequado suprimento de nutrientes no solo, dessa maneira assegurando um adequado crescimento da 
planta. A falta ou a não aplicação desses nutrientes necessários contribui para acelerar a degradação das pastagens cultivadas, consequentemente a diminuição no ganho de peso animal por área. No entanto, é importante determinar os níveis críticos desses elementos para que se possa realizar um trabalho sem que haja qualquer tipo de degradação. A deficiência desses nutrientes no solo será fator determinante na estrutura física das plantas (colmos finos, raquíticos, e pouco resistentes ao tombamento, enquanto as folhas são pequenas, amareladas, ou amarelo-alaranjadas, com manchas necróticas nas pontas e nas margens aumentado a intensidade de secagem das folhas), na produtividade (quantidade de matéria seca) e na qualidade (teor de proteína). Os objetivos desta revisão de literatura são discutir as exigências nutricionais das espécies de gramíneas dos gêneros Panicum, Brachiaria, Andropogon, Cynodon, Pennisetum e Cenchrus, com suas respectivas peculiaridades, que condicionam a produção de forragem.

Palavras-chave: Andropogon, Brachiaria, Cenchrus, Cynodon, Panicum, Pennisetum

\title{
Some considerations on the nutritional requirements of tropical forage grasses
}

\begin{abstract}
Over the years have studied soils, forage crops and nutrition of ruminants separately. However the soil-plant-animal is complex and interdependent, which can lead to failure of the production system if the inclusion of forage is inadequate. When thinking about deployment or persistence of cultivated pastures of the main factors to take into consideration is the adequate supply of nutrients in the soil, thus ensuring an adequate plant growth. Lack or nonapplication of these nutrients contributes to accelerate the degradation of cultivated pastures, hence the decrease in live weight gain per area. However, it is important to determine the levels of these critical elements so you can do a job without any kind of degradation. The deficiency of these nutrients in the
\end{abstract}


SILVA, G.L.S. et al. Algumas considerações sobre as exigências nutricionais das gramíneas forrageiras tropicais. PUBVET, Londrina, V. 8, N. 11, Ed. 260, Art. 1724, Junho, 2014.

soil will be a determining factor in the physical structure (thin stems, stunted, and somewhat resistant to tipping, while the leaves are small, yellowish, or yellow-orange, with necrotic spots on the tips and margins increased intensity drying of leaves), yield (dry matter) and quality (protein). The objectives of this review are to discuss the nutritional requirements of the species of grasses of the genera Panicum, Brachiaria, Andropogon, Cynodon, Pennisetum and Cenchrus, and their respective peculiarities, that affect forage production.

Keywords: Andropogon, Brachiaria, Cenchrus, Cynodon, Panicum, Pennisetum

\section{Introdução}

Com a expansão da atividade pecuária e o aumento da comercialização dos produtos (carne e leite) no mercado, torna-se crescente a demanda pela eficiência em produtividade, resultando na busca de técnicas que aumentem a produção sem que haja perdas na qualidade das pastagens e/ou elevação dos custos.

Nos últimos anos as pastagens cultivadas no Brasil vêm ganhando espaço entre os produtores em relação às nativas, principalmente devido ao seu potencial de produção e sua adaptação às condições climáticas. Estima-se que dos 180 milhões de hectares de pastagens do país, cerca de 100 milhões de hectares são de pastagens plantadas (IBGE, 2009). Em grande parte dessas pastagens são utilizadas as cultivares do gênero Panicum, Brachiaria, Andropogon, Cynodon, Pennisetum e a espécie Cenchrus ciliaris por apresentarem características distintas.

De fato, essas espécies predominam nas áreas de pastagens cultivadas do país e, sem dúvida, representam boa parte dos esforços e recursos investidos em programas de pesquisa, melhoramento e introdução de novas espécies e cultivares. No entanto, em termos práticos, os benefícios desse potencial de produção dificilmente têm sido realizados, uma vez que os indicadores produtivos e zootécnicos apontam para aumentos de produtividade muito modestos em relação ao que poderia ser obtido (NASCIMENTO JÚNIOR et al., 
2004). Isso nos leva a crer, que as informações disponíveis para o manejo adequado dessas plantas não estão sendo empregadas corretamente.

Ao longo dos anos têm-se estudado os solos, as plantas forrageiras e a nutrição dos ruminantes separadamente. Entretanto o sistema solo-plantaanimal é complexo e interdependente, o que pode levar ao insucesso do sistema produtivo quando a inclusão da forrageira é inadequada.

No processo de implantação de uma cultivar, não se deve levar em consideração somente o alto potencial forrageiro da planta, outros fatores como as condições climáticas e do solo influenciam diretamente os níveis de produtividade e qualidade da espécie escolhida. Portanto, as cultivares incorporadas no sistema de produção além de suprir as necessidades nutricionais do rebanho, sejam capaz de otimizar o ganho de peso animal por área sem elevar o custo de produção.

Os objetivos desta revisão de literatura são discutir as exigências nutricionais das espécies de gramíneas dos gêneros Panicum, Brachiaria, Andropogon, Cynodon, Pennisetum e Cenchrus ciliaris com suas respectivas peculiaridades, que condicionam a produção de forragem.

\section{Revisão de Literatura}

\subsection{Considerações gerais}

A importância das pastagens pode ser facilmente caracterizada, pois estas constituem a base dos sistemas de produção de bovinos, o que evidencia sua importância e a necessidade de se buscarem práticas de manejo que resultem em maior eficiência desses sistemas. Calcula-se que aproximadamente $88 \%$ do plantel de bovinos brasileiros sejam manejados única e exclusivamente em pastagens (ANUALPEC, 2004). De acordo com a FAO (2002), as pastagens apresentam grande importância territorial no Brasil, quando se observa que 70 $\%$ das terras do setor agropecuário, o qual constitui $30 \%$ do território nacional, são ocupadas por pastagens (FAO, 2002). 
SILVA, G.L.S. et al. Algumas considerações sobre as exigências nutricionais das gramíneas forrageiras tropicais. PUBVET, Londrina, V. 8, N. 11, Ed. 260, Art. 1724, Junho, 2014.

Nos últimos anos o elevado potencial de produção das pastagens tropicais tem sido ressaltado e justificado pela disponibilidade de espécies forrageiras extremamente produtivas e adaptadas ao pastejo como é o caso dos capins dos gêneros Panicum, Brachiaria, Andropogon, Cynodon, Pennisetum e Cenchrus ciliaris.

Entretanto, para que o potencial dessas pastagens se manifeste, é necessário que se utilizem espécies forrageiras adaptadas às condições edafoclimáticas locais. O uso indevido de forrageiras não adaptadas poderá trazer efeitos negativos, não só do ponto de vista econômico, mas também ecológico. Esses efeitos se manifestam quando da substituição do pasto por espécies indesejáveis, sem valor forrageiro, ou pelo aparecimento, em regiões montanhosas, de áreas erodidas. O resultado final é a perda irreversível da camada superficial do solo e diminuição da capacidade de suporte da pastagem (BOTREL et al., 1999). Nesse sentido, a análise do crescimento e desenvolvimento de plantas forrageiras constitui importante estratégia tanto para a caracterização do potencial de produção quanto para a definição do potencial de uso de determinado ecossistema para a produção animal (NASCIMENTO JÚNIOR et al., 2002).

O hábito de crescimento das pastagens pode proporcionar aumento da degradação dos solos, já que uma cobertura vegetal inadequada em solos com declividade pode apresentar erosões e até mesmo voçorocas. Nestas áreas, devem-se priorizar as forrageiras que tem o hábito de crescimento prostrado (rasteiro), pois essas plantas oferecem uma maior cobertura do solo que as de hábito ereto que apresentam uma maior área exposta ao solo. Quando a pastagem de crescimento ereto está muito alta, os detritos orgânicos ajudam, em parte, a cobrir o solo, protegendo-o, até certo ponto, contra o impacto direto das gotas de chuvas e dos ventos.

As pastagens apresentam estacionalidade de crescimento durante o ano; toda via atingem, em determinado momento, sua melhor qualidade de pastejo, dependente das condições climáticas: temperatura, luminosidade e disponibilidade hídrica (VALLENTINE, 1990). Fica evidente, portanto, a íntima 
SILVA, G.L.S. et al. Algumas considerações sobre as exigências nutricionais das gramíneas forrageiras tropicais. PUBVET, Londrina, V. 8, N. 11, Ed. 260, Art. 1724, Junho, 2014.

relação entre fatores ambientais e a ocorrência e distribuição das plantas forrageiras, mostrando a necessidade de se conhecer a disponibilidade destes fatores de crescimento e as características ecológicas e fenológicas das plantas a serem trabalhadas, para que se possa obter produtividade e longevidade dentro de uma filosofia de exploração racional de pastagens (SILVA, 1995).

\subsection{Principais nutrientes para plantas forrageiras ( N, P e K)}

Quando se pensa em implantação ou persistência das pastagens cultivadas um dos principais fatores a levar em consideração, é o apropriado suprimento de nutrientes no solo, dessa maneira assegurando um adequado crescimento da planta. A falta ou a não aplicação desses nutrientes necessários contribui para acelerar a degradação das pastagens cultivadas, consequentemente a diminuição no ganho de peso animal por área. No entanto, é importante determinar os níveis críticos desses elementos para que se possa realizar um trabalho sem que haja qualquer tipo de degradação.

A deficiência desses nutrientes no solo será fator determinante na estrutura física das plantas (colmos finos, raquíticos e pouco resistentes ao tombamento, enquanto as folhas são pequenas, amareladas, ou amareloalaranjadas, com manchas necróticas nas pontas e nas margens aumentado a intensidade de secagem das folhas), na produtividade (quantidade de matéria seca) e na qualidade (teor de proteína).

Para a produção ser efetiva, todos os outros nutrientes devem estar presentes em quantidades adequadas e equilibradas. Além disso, a quantidade de nutrientes extraída do solo pela planta forrageira será maior quanto maior for a produção de forragem (WERNER, 1996).

\subsection{Plantas do gênero Panicum maximum Jacq.}

As gramíneas do gênero Panicum possuem uma grande variabilidade genética, com inúmeros ecótipos distintos, ocorrendo especialmente no leste da África, com mais de uma dúzia de variedades botânicas já descritas (HERLING et al., 2000). São algumas das espécies de plantas forrageiras mais 
SILVA, G.L.S. et al. Algumas considerações sobre as exigências nutricionais das gramíneas forrageiras tropicais. PUBVET, Londrina, V. 8, N. 11, Ed. 260, Art. 1724, Junho, 2014.

importantes para a produção de bovinos nas regiões de climas tropical e subtropical (SOUZA, 1999).

A área ocupada pela espécie Panicum maximum Jacq. corresponde a aproximadamente $20 \%$ de toda a área de pastagens cultivadas no Brasil (em torno de 100 milhões de hectares), suprindo 30\% do mercado de sementes forrageiras (Abrasem, 2004). Para Corsi (1986), essas espécies são caracterizadas pelo seu grande potencial de produção de forragem, e durante décadas o capim colonião foi considerado insuperável em termos de qualidade para a engorda de bovino no Brasil central (Tabela 1).

Tabela 1. Desempenho agronômico de cultivares de Panicum maximum Jacq.

\begin{tabular}{lcccc}
\hline \multirow{2}{*}{ Variável } & \multicolumn{4}{c}{ Cultivares } \\
\cline { 2 - 5 } & Colonião & Tanzânia & Mombaça & Massai \\
\hline Altura da planta $(\mathrm{m})$ & 1,4 & 1,2 & 1,7 & 0,6 \\
PMS (t/ha/ano) & 14 & 26 & 33 & 15,3 \\
\% folhas & 62 & 80 & 82 & 80 \\
\hline
\end{tabular}

Fonte: Adaptado de Jank (1995) e Embrapa (2001).

As pastagens apresentam estacionalidade de crescimento durante o ano; todavia atingem, em determinado momento, sua melhor qualidade de pastejo, dependente das condições climáticas: temperatura, luminosidade e disponibilidade hídrica (VALLENTINE, 1990). De acordo Skerman e Riveros (1992), a temperatura ótima para o crescimento é de $19,1^{\circ} \mathrm{C}$ e $22,9^{\circ} \mathrm{C}$, índices pluviométricos próximos de $1300 \mathrm{~mm}$ (MCCOSKER e TEITEZEL, 1975) e sensibilidade a solo ácido (WERNER, 1986).

Segundo Corsi e Santos (1995), apesar do aparente conhecimento que técnicos e pecuaristas têm sobre $P$. maximum, na prática isso não ocorre, podendo ser demonstrado quando se espera produções elevadas durante o inverno, justamente quando esta espécie apresenta seu pior desempenho devido à sua elevada estacionalidade de produção.

Dentre os diversos cultivares, Panicum maximum cv. Mombaça (capimmombaça), cv. Tanzânia (capim-tanzânia) e cv. Massai (capim-massai) 
SILVA, G.L.S. et al. Algumas considerações sobre as exigências nutricionais das gramíneas forrageiras tropicais. PUBVET, Londrina, V. 8, N. 11, Ed. 260, Art. 1724, Junho, 2014.

adquiriram grande destaque nas áreas de pastagens cultivadas do país e, por essa razão, têm concentrado boa parte dos esforços e recursos investidos em pesquisa (Tabela 2 ).

Tabela 2. Alguns dados relativos aos grupos e cultivares da espécie Panicum maximum.

\begin{tabular}{lccc}
\hline Grupo & Cultivar & Instituição & Ano da 1a utilização \\
\hline Tradicional & Colonião & Acidental & Século 18 \\
Novo apomítico & Tanzânia-1 & EMBRAPA & 1990 \\
& Mombaça & EMBRAPA & 1993 \\
Híbrido & Massai & EMBRAPA & 2001 \\
\hline
\end{tabular}

*Embrapa - Empresa Brasileira de Pesquisa Agropecuária

Fonte: Adaptado de Souza (1999).

Outro fator importante ligado à degradação das pastagens de $P$. maximum foi a reposição e a manutenção da fertilidade do solo. O modelo extrativista de exploração de pastagens, bastante comum no país, mostrou-se incapaz de garantir a produtividade, a qualidade e a persistência da espécie, de elevada exigência em fertilidade do solo (VILELA et al., 2000).

De modo geral, existem diferenças entre as plantas forrageiras no grau de tolerância à acidez do solo, mas os capins do gênero Panicum geralmente estão entre os mais sensíveis. Como recomendação geral para Panicum, observa-se que o valor médio, para a porcentagem de saturação de bases desejadas, encontra-se entre 45 e 50\%, preconizado por técnicos da Embrapa gado de Corte, ao de 60\% (MONTEIRO, 1995) e entre $70-80 \%$ (HERLING et al., 1998).

\subsection{Plantas do gênero Brachiaria}

O gênero Brachiaria contém cerca de 97 espécies, com limites taxonômicos mal definidos, distribuída por toda a zona tropical do planeta (RENVOIZE et al., 1996). Essas espécies crescem dentro de uma grande variedade de "habitats" sendo encontradas em regiões alagadas, desérticas, 
SILVA, G.L.S. et al. Algumas considerações sobre as exigências nutricionais das gramíneas forrageiras tropicais. PUBVET, Londrina, V. 8, N. 11, Ed. 260, Art. 1724, Junho, 2014.

em plena luz ou sombreadas, mas são encontradas principalmente nas savanas (BUXTON e FALES, 1994).

Embora sejam descritas como plantas daninhas agressivas e de controle custoso em áreas agrícolas, o interesse agronômico do gênero está relacionado ao seu uso como plantas forrageiras em pastagens (VALLE et al., 2000), sendo usadas para tal finalidade principalmente na América Tropical, a B. brizantha, B. decumbens, B. humidicola, B. mutica, B. ruzizienses (BUXTON e FALES, 1994).

De toda a área cultivada com pastagens no Brasil, 70 a $80 \%$ são formados por espécie do gênero Brachiaria. Atualmente, as espécies $B$. brizantha, $B$. decumbens, $B$. humidicola e $B$. ruzizienses podem der consideradas as mais cultivadas no País (SOARES FILHO, 1994).

Adapta-se bem até $3.000 \mathrm{~m}$ de altitude, precipitação anual ao redor de $700 \mathrm{~mm}$ e cerca de cinco meses de seca no inverno (SOARES FILHO, 1994). Segundo Stür et al. (1996), a taxa de crescimento de espécies de Brachiaria começa a decrescer a partir de temperaturas médias abaixo de $24^{\circ} \mathrm{C}$ e a cessar à temperatura infra-ótima de $15^{\circ} \mathrm{C}$, em espécies menos tolerantes ( $B$. humidicola e $B$. ruziziensis) e de $12^{\circ} \mathrm{C}$, em espécies tolerantes (B. decumbens e B. mutica).

As espécies de Brachiaria apresentam vantagens como elevada produção de forragem, tolerância a pragas em especial as cigarrinhas das pastagens, alta resposta a aplicação de fertilizantes, boa qualidade de forragem e alta produção de raízes e sementes, tornando o gênero, o campeão de vendas de semente no país (SOARES FILHO, 1994).

Quanto ao seu potencial produtivo, segundo Ghisi e Pedreira, (1987), apresentam elevada produção de massa verde e responde bem a adubações, com produções de até 36 toneladas de massa seca por hectare por ano. No entanto em condições normais a produtividade tende a cair, como demonstrado na Tabela 3. 
SILVA, G.L.S. et al. Algumas considerações sobre as exigências nutricionais das gramíneas forrageiras tropicais. PUBVET, Londrina, V. 8, N. 11, Ed. 260, Art. 1724, Junho, 2014.

Tabela 3. Produtividade de matéria seca (t/ha) dos cultivares comerciais de braquiárias sob cortes, em diversos locais.

\begin{tabular}{lcc}
\hline Local & Espécie & Produtividade \\
\hline Nova Odessa, SP & B. decumbens & 9,3 \\
& B. ruziziensis & 10,8 \\
\hline Belém, PA & B. humidicola & $11-25$ \\
& B. ruzizienses & $14-22$ \\
\hline Planaltina, DF & B. ruzizienses & $4-17$ \\
\hline
\end{tabular}

Fonte: Adaptado de Pedreira e Matos (1981), Simão Neto e Serrão (1974), Thomas e Andrade (1984).

\subsection{Plantas do gênero Cynodon}

A origem do gênero Cynodon é atribuída por alguns autores às ilhas Bermudas, próximos dos Estados Unidos. Outros, porém, citam a região do Mediterrâneo e mesmo o sul da Ásia. Em virtude das ocorrências da diversidade de formas, tudo indica ser a África o centro básico de sua origem (MITIDIERI, 1992).

Atualmente têm surgido algumas forrageiras promissoras do gênero Cynodon, resultantes de trabalhos de melhoramento genético realizados nas Universidades da Geórgia e da Flórida, nos Estados Unidos (HILL et al., 1996) e que foram rapidamente introduzidos e disseminados em nosso meio, aparentemente de maneira mais rápida que as informações a eles pertinentes (PEDREIRA et al., 1998).

Dentre os cultivares lançados pelos programas de melhoramento e que hoje mais largamente são utilizados no Brasil está o Tifton 85 que é tido como o melhor híbrido desenvolvido no momento, caracterizando-se por ser bastante produtivo, com elevado valor nutricional, boa digestibilidade, e grande resistência ao frio (HILL et al., 1993)

De um modo geral, capins do gênero Cynodon apresentam, em nossas condições, um elevado potencial de produção por animal e por área (CORSI e MARTHA JÚNIOR, 1998), grande flexibilidade de manejo (NUSSIO et al., 1998) e forragem de boa qualidade (HILL et al., 1996). 
SILVA, G.L.S. et al. Algumas considerações sobre as exigências nutricionais das gramíneas forrageiras tropicais. PUBVET, Londrina, V. 8, N. 11, Ed. 260, Art. 1724, Junho, 2014.

Para esse gênero, os solos devem ser de fertilidade média a boa, não se desenvolvendo em solos ácidos e de baixo nível de cálcio (NASCIMENTO JÚNIOR, 1981, citado por BRENNECKE, 2002).

Tabela 4. Produção de matéria seca e digestibilidade in vitro da matéria seca (DIVMS) de quatro cultivares de Cynodon (media de 3 anos).

\begin{tabular}{lcccc}
\hline Item & \multicolumn{4}{c}{ Cultivares } \\
\cline { 2 - 5 } & Tifton 85 & Tifton 68 & Tifton 44 & Coastal \\
\hline Produção (t/ha) & 18,6 & 15,2 & 15,7 & 15,5 \\
DIVMS (\%) & 60,3 & 63,6 & 55,0 & 54,3 \\
\hline
\end{tabular}

Fonte: Adaptado de Hill et al., (1993)

\subsection{Plantas do gênero Cenchrus}

O capim-buffel (Cenchrus ciliaris) é uma gramínea tropical resistente à seca, que se desenvolve satisfatoriamente em solos leves e profundos, podendo ser cultivado em solos argilosos, desde que bem drenados. Adapta-se bem nas regiões semi-áridas do Nordeste, com precipitações de 350 a 700 mm anuais. Originário da África, o capim-buffel é uma espécie perene, de porte variando de 0,6 a 1,5 m de altura, dependendo da variedade ou cultivar.

A Austrália é um dos países que mais atenção têm dedicado ao cultivo de capim-buffel. Em 1981, este país possuía cerca de dois milhões de hectares plantados no estado de Queensland, dos quais $60 \%$ em estado puro e $40 \%$ consorciado com outras gramíneas e/ou leguminosas (AYERZA, 1981).

A aceitação do capim-buffel pelos pecuaristas, como a planta forrageira mais adaptada às condições semiáridas do Nordeste, motivou diversas avaliações cujos resultados abrangeram vários aspectos do seu cultivo, manejo e utilização (OLIVEIRA, 1993). De maneira geral, apresenta melhor crescimento em solos leves e profundos, podendo também crescer satisfatoriamente em solos argilosos com boa drenagem, e seu enraizamento é profundo. Seu valor nutritivo é alto, com alta digestibilidade da matéria seca (MS) e da proteína bruta, e possui boa aceitabilidade. 
SILVA, G.L.S. et al. Algumas considerações sobre as exigências nutricionais das gramíneas forrageiras tropicais. PUBVET, Londrina, V. 8, N. 11, Ed. 260, Art. 1724, Junho, 2014.

A produtividade de diversas variedades do capim-buffel varia de lugar para lugar, de acordo com a maior ou menor adaptação às condições locais, com produtividade variando de 8 a 12 t de $\mathrm{MS} \mathrm{ha}^{-1} \mathrm{ano}^{-1}$ (OLIVEIRA, 1981).

\subsection{Plantas do gênero Andropogon}

O gênero Andropogon contém cerca de cem espécies anuais e perenes dispersas nos trópicos, principalmente na África e América (CLAYTON e RENVOIZE, 1982).

Uma vez estabelecida, a gramínea tem alto potencial produtivo, é muito persistente e possui habilidade para competir com plantas invasoras, por conta de seu porte e sistema radicular (SKERMAN e RIVEROS, 1990). Segundo Bogdan (1977), essa gramínea é capaz de suportar até nove meses de seca. Essa tolerância à seca está relacionada com a profundidade de seu sistema radicular que pode extrair água disponível até a profundidade de 1,20 m (GOEDERT et al., 1985). Requer precipitação anual acima de 400 mm, idealmente com estação seca de três a quatro meses (JONES, 1979) e temperaturas entre $18^{\circ}$ e $28^{\circ} \mathrm{C}$ são as mais adequadas para ele produzir bem. Embora tolere a ocorrência de geadas rápidas, não se adapta bem em localidades onde a temperatura media mínima no mês mais frio do ano que atinge $4,4^{\circ} \mathrm{C}$ (PAULINO, 1979).

O capim-andropógon é uma forrageira adaptada a solos de textura arenosa e argilosa, principalmente aqueles de baixa fertilidade, com baixo $\mathrm{pH}$ $(4,3)$ e altos níveis $(81 \%)$ de alumínio tóxico (COUTO et al., 1985).

O capim-andropógon (Andropogon gayanus Kunth cv. Planaltina), recomendado para a região dos cerrados com base em resultados experimentais obtidos em solos ácidos e com baixa fertilidade natural, destaca-se pelo seu bom desempenho mesmo sob condições adversas (GOEDERT et al., 1985). Esse capim apresenta capacidade de rebrota após o fogo, utilizado para a renovação e limpeza das pastagens a fim de aumentar a produção das forrageiras e melhorar a aceitabilidade pelos animais (SANTOS et 
al., 1992), resiste ao ataque das cigarrinhas-das-pastagens e apresenta bom teor de proteína bruta (COSTA et al., 2001).

Comparando com outras espécies mais exigentes, observa-se que embora adaptadas a solos de baixa fertilidade, o capim-andropogon responde bem à calagem e à aplicação de fertilizantes (COUTO et al., 1988). Essa gramínea produz entre 20 e 30 toneladas de MS ha ${ }^{-1} a n o^{-1}$. Na fase de pleno desenvolvimento, apresenta taxas de crescimento variando entre 46 e $71 \mathrm{~kg}$ de MS ha-1 dia $^{-1}$ (THOMAS et al., 1981). Sob irrigação e adubação nitrogenada, o capim-andropogon poderá produzir 3 a 4 t/ha a cada 28 dias (MAGALHÃES et al., 2012).

\subsection{Plantas do gênero Pennisetum}

Gramínea originária da África e introduzida no Brasil em 1920, através de mudas provenientes dos Estados Unidos da América (DE FARIAS, 1994). O capim-elefante (Pennisetum purpureum) é uma forrageira largamente utilizada na pecuária nacional, seja para corte, silagem ou sistema de pastejo sob lotação rotacionada, em razão de sua alta produtividade que pode variar de 10 a 80 toneladas de MS ha- ${ }^{-1}$ no $^{-1}$ (CORSI e NUSSIO, 1992; CÓSER et al., 2002; MAGALHÃES et al., 2007).

PEREIRA (1993), considerando as principais características com função discriminatória e importância agronômica, bem como a constituição genética, definiu grupos com relação aos tipos básicos:

Grupo Anão: as cultivares deste grupo são mais adaptadas para pastejo em função do menor comprimento dos entrenós.

Grupo Cameroon: apresentam plantas de porte ereto, colmos grossos, predominância de perfilhos basilares, folhas largas, florescimento tardio, ou ausente, e touceiras densas.

Grupo Napier: as cultivares deste grupo apresentam variedades de plantas com colmos grossos, folhas largas, época de florescimento intermediaria e touceiras abertas. 
Grupo dos Híbridos: resultantes do cruzamento entre espécies de Pennisetum, principalmente $P$. purpureum e $P$. americanum.

Segundo Moss (1964), Alcântara e Bufarah (1983) e Jacques (1994) destacaram as seguintes características agronômicas:

Temperatura - de 18 a $30^{\circ} \mathrm{C}$, sendo $24^{\circ} \mathrm{C}$ uma boa temperatura. Porém é importante a amplitude dessa temperatura. Dependendo do cultivar, pode suportar o frio.

Precipitação - vegeta em regiões quentes e úmidas com precipitação anual de mais de $1.000 \mathrm{~mm}$, porém o mais importante é sua distribuição ao longo do ano, por ser uma forrageira muito estacional, onde $70-80 \%$ de sua produção ocorrem na época das águas. Possui baixa tolerância à seca, podendo atravessar a estação seca com baixa produção se possuir raízes profundas (bem estabelecida).

Solo - adapta-se a diferentes tipos de solo, com exceção dos solos mal drenados, com possíveis inundações. São encontradas em barrancas de rios, regiões úmidas e orlas de floresta. Não foram observados registros de tolerância à salinidade.

Fertilidade - exigente em relação aos nutrientes e não tolera baixo $\mathrm{pH}$ e alumínio no solo.

\section{Considerações Finais}

A reposição de nutrientes no solo dependerá do tipo de manejo dos rebanhos e das pastagens.

Fica evidente que o tipo de solo, nutrientes disponíveis e fatores edafoclimáticos influenciam tanto na produção como na qualidade da planta forrageira com reflexos imediatos no desempenho animal.

\section{Referências Bibliográficas}

ALCÂNTARA, P.B., BUFARAH, G. Plantas forrageiras: gramíneas e leguminosas. São Paulo, Editora Nobel, $2^{a}$ ed., 1983, 150p. 
ANUALPEC 2004, Anuário da Pecuária Brasileira. São Paulo. FNP, 2004. 376p.

ASSOCIAÇÃO BRASILEIRA DE SEMENTES - ABRASEM. Disponível em: http://<www.abrasem.br.> Acesso em 1/12/2004.

AYERZA, R. El buffel grass: utilidad y manejo de uma promissora graminea. Buenos Aires: Editoral Hemisfério Sur, 1981. 139p.

BOGDAN, A.V. Tropical pasture and fodder plants. New York, Longman, 1977, 465p.

BOTREL, M.A. et al. Avaliação de gramíneas forrageiras na região sul de minas gerais. Pesquisa Agropecuária Brasileira. Brasília, v.34, n.4, p.683-689, 1999.

BRENNECKE, K. Efeito de doses de sódio e nitrogênio na composição bromatológica, química e digestibilidade in vitro do capim-coastcross (Cynodon dactylon (L.) Pers.), em duas idades de corte. 2002, 73f. Dissertação (Mestrado) - Faculdade de Zootecnia e Engenharia de Alimentos, Universidade de São Paulo, Pirassununga, SP.

BUXTON, T.R.; FALES, S.L. Plant enviroment and quality. In: FAHEY JR., G.C. (Ed.). Forage quality, evalution and utilization. Madison: American Society of Agronomy, 1994. p.1551999.

CLAYTON, W.D.; RENVOIZE, S.A. Gramineae (Part 3). In : POLHILL, R.M. (Ed.). Flora of Tropical East Africa. Balkema, Rotterdam, Netherlands, 1982, p.451-898.

CORSI, M.; MARTHA JÚNIOR, G.B. Manejo de pastagens para a produção de carne e leite. In: SIMPÓSIO SOBRE MANEJO DA PASTAGEM, 15., Piracicaba, 1998. Anais... Piracicaba: FEALQ, 1998. p.55-84.

CORSI, M.; SANTOS, P.M. Potencial de produção do Panicum maximum. In: SIMPOSIO SOBRE MANEJO DA PASTAGEM, 12., Piracicaba, 1995. Anais... Piracicaba: FEALQ, 1995. p.275-303.

CORSI, M.; NUSSIO, L.G. Manejo do capim elefante: correção e adubação do solo. In: SIMPÓSIO SOBRE MANEJO DA PASTAGEM, 10., Piracicaba, 1992. Anais... Piracicaba: FEALQ, 1992, p.87-116.

CORSI, M.; Pastagens de alta produtividade. In: CONGRESSO BRASILEIRO DE PASTAGENS, 8., 1986, Piracicaba. Anais... Piracicaba: FEALQ, 1986. p.499-512.

CÓSER, A.C. et al. Avaliação de metodologias para a estimativa da disponibilidade de forragem em pastagem de capim-elefante. Ciência Agrotécnica, Lavras, v.26, n.3, p.589-598, 2002.

COSTA, N. de L. et al. Formação e manejo de pastagens de capim-andropógon em Rondônia. Porto Velho: Embrapa Rondônia, 2001. 2p. (Recomendações Técnicas, 25).

COUTO, W. et al. A adubação para o estabelecimento de pastagens consorciadas nos solos de Cerrado. In: SIMPÓSIO SOBRE O CERRADO. 6., Embrapa, Brasília-DF, 1988. Anais... Brasília, 1988, p.61-78.

COUTO, W. et al. The residual effect of $\mathrm{P}$ and lime on the performance of four tropical grasses in a high P fixing Oxisol. Agronomy Journal, Madison, v.77, p.534-542, 1985.

DE FARIAS, V.P. et al. Evolução do uso de pastagens para bovinos. In: SIMPÓSIO SOBRE O MANEJO DE PASTAGENS, 13., 1996. Piracicaba. Anais... Piracicaba: FEALQ, 1996. p.1-14.

EMPRESA BRASILEIRA DE PESQUISA E AGROPECUÁRIA - EMBRAPA. Capim-massai (Panicum maximum cv. Massai): alternativa para diversificação de pastagens. Campo Grande: Embrapa Gado de Corte, 2001. 8p. (Comunicado Técnico, 65).

FAO. http://www.fao.org (12 de novembro de 2002). 
GHISI, O.M.A.A.; PEDREIRA, J.V.S. Características agronômicas das principais Brachiarias sp. In: ENCONTRO PARA DISCURSÃO SOBRE CAPINS DO GÊNERO Brachiaria, 1., 1986, Nova Odessa. Anais... Nova Odessa: Instituto de Zootecnia, 1986. p.19-58.

GOEDERT, W. et al. Desenvolvimento radicular do capim-andropógon e sua relação com o teor de cálcio no perfil do solo. Revista Brasileira de Ciência do Solo, Campinas, v.9, p.89-91, 1985.

HERLING, V.R. et al. Efeitos de períodos de descanso e de matérias secas residuais sobre o capim-mombaça (Panicum maximum Jacq.) sob pastejo. 1. Matéria seca disponível. In: REUNIÃO ANUAL DA SOCIEDADE BRASILEIRA DE ZOOTECNIA, 35., Botucatu, 1998. Anais... Botucatu: SBZ, 1998, CD-ROM.

HERLING, V.R. et al. Tobiatã, Tanzânia e Mombaça. In: SIMPOSIO SOBRE MANEJO DE PASTAGENS 17., Piracicaba, 2000. A planta forrageira no sistema de produção. Anais... Piracicaba: FEALQ, 2000. p.21-64

HILL, G.M. et al. Forage quality and grazing steer performance from Tifton 85 and Tifton 78 bermudagrass pastures. Journal of Animal Science, v.71, p.3219-3225, 1993.

HILL, G.M. et al. Tifton 85 bermudagrass utilization in beef, dairy, and hay production. In: WORKSHOP SOBRE O POTENCIAL FORRAGEIRO DO GÊNERO Cynodon, Juiz de Fora, 1996. Anais... Juiz de Fora: EMBRAPA, CNPGL, 1996. p.139-150.

IBGE - Instituto Brasileiro de Geografia e Estatística. Disponível em: <http:/www.ibge.gov.br>. Acesso em: 28 de maio. 2009.

JACQUES, A.V.A. Caracteres morfo-fisiológicos e suas aplicações como manejo. In: CARVAlHO, M.M., ALVIM, M.J., XAVIER, D.F. et al. (Eds.) Capim elefante: produção e utilização. Coronel Pacheco: Embrapa Gado de Leite, 1994, p.31-47.

JANK, L. Melhoramento e seleção de variedades de Panicum maximum. In: SIMPÓSIO SOBRE MANEJO DA PASTAGEM, 12., Piracicaba, 1995. Anais... Piracicaba: FEALQ, 1995. p.21-58.

JONES, C.A. The potencial of Andropogon gayanus Kunth in the Oxisol and Ultisol Savannas of Tropical America. Herbage Abstract, v.49, p.1-8, 1979.

MAGALHÃES, J. A. et al. Eficiência do nitrogênio, produtividade e composição do capimandropogon sob irrigação e adubação. Archivos de Zootecnia, v. 61, p. 577-588, 2012.

MAGALHÃES, J. A . et al. Efeito do nitrogênio e da idade de corte sobre a produção de cultivares de capim-elefante. Pasturas Tropicales, v. 29, p. 68-75, 2007.

MARTINEZ, H.E.P. Níveis críticos de fósforo em Brachiaria decumbens (Stapf) Prains, Brachiaria humidicola (Rendle) Schweickerdt, Digitaria decumbens Stent, Hyparrhenia rufa (Ness) Stapf, Melinis minutiflora Pal de Beauvy, Panicum maximum Jacq. e Pennisetum purpureum Shum. Piracicaba, 1980. 90p. Dissertação (Mestrado) Escola Superior de Agricultura Luiz de Queiroz, USP, 1980.

MCCOSKER, T.H.; TEITEZEL, J.K. A reiview of guinea grass (Panicum maximum) for the wet tropics of Australia. Tropical Grasslands, v.9, n.3, p.177-190, 1975.

MITIDIERI, J. Manual de gramíneas e leguminosas para pastos tropicais, 2a Ed. 1992, 198p.

MONTEIRO, F.A. Nutrição mineral e adubação. In: SIMPÓSIO SOBRE MANEJO DA PASTAGEM, 12., Piracicaba, 1995. Anais... Piracicaba: FEALQ, 1995, p.219-244.

MOSS, D.N. Some aspects of microclimatology important in forage plant physiology. In: Forage plant physiology an soil relationships. ASA Special publications MadisonWinsconsin, 1964. 
NASCIMENTO JÚNIOR, D. et al. Perspectivas futuras do uso de gramíneas em pastejo. In: SIMPÓSIO FORRAGEIRAS E PRODUÇÃO EM PASTAGENS, 2004, Campo Grande. Anais... Campo Grande, MS: EMBRAPA CNPGC, 2004, p.130-141.

NUSSIO, L.G. et al. Valor alimentício em plantas do gênero Cynodon. In: SIMPÓSIO SOBRE MANEJO DA PASTAGEM, 15., Piracicaba, 1998. Anais... Piracicaba: FEALQ, 1998. p.203-242.

OLIVEIRA, M.C. Capim-buffel: produção e manejo nas regiões secas do Nordeste. Petrolina: Embrapa - CPATSA, 1993. 18p (Circular Técnica, 27).

OLIVEIRA, M.C. 0 capim-buffel nas regiões secas do nordeste. Petrolina: EMBRAPACPATSA, 1981. 19p. (Circular Técnica, 5).

PAULINO, V.T. O capim-gambá (Andropogon gayanus Kunth) na América tropical. Zootecnia, São Paulo, v.17, n.4, p.239-252, 1979.

PEDREIRA, J.V. et al.Condições edafo-climáticas para produção de Cynodon spp. In: SIMPÓSIO SOBRE MANEJO DA PASTAGEM, 15. Piracicaba 1998. Anais... Piracicaba: FEALQ, 1998. p. 85113.

PEDREIRA, J.V.; MATOS, H.B. Crescimento estacional de vinte e cinco espécies de variedades de capins. Boletim da Indústria Animal, Nova Odessa, v.38, n.2, p.117-143, 1981.

PEREIRA, A.V. Escolha de variedades de capim-elefante. In: PEIXOTO, A.M., MOURA, J.C., FARIA, V.P. (Eds.) Simpósio sobre Manejo da Pastagem, 10., Piracicaba, 1993. Anais... Piracicaba: FEALQ, 1993, p.47-62.

RENVOIZE, P. et al. Morphology, taxonomy and natural distribution of Brachiaria. In: MILES, J.W.; MAASS, B.L.; VALLE, C.B. (Ed.). Brachiaria: biology, agronomy and improvement. Cali: CIAT/Brasília: Embrapa-CNPGC, 1996, p.1-15.

SANTOS, D. et al. Queimadas e erosão do solo. Informe Agropecuário. Belo Horizonte, v. 16, p. 62-68, 1992.

SILVA, S.C. Condições edafo-climáticas para a produção de Panicum sp.. In: SIMPÓSIO SOBRE MANEJO DA PASTAGEM, 12., Piracicaba, 1995. Anais... Piracicaba: FEALQ, 1995. p.129-146.

SIMÃO NETO, M.; SERRÃO, E.A.S. Capim quicuio da Amazônia (Brachiaria sp.). Belém: IPEAN, 1974. 17p. (Boletim Técnico, 58).

SKERMAN, P.J; RIVEROS, F. Gramíneas tropicales. Rome: FAO, 1990. 834p. (FAO Plant Production and Protection Series, 23).

SKERMAN, P.J; RIVEROS, F. Gramíneas tropicales. Rome: FAO, 1992. 849p. (FAO Producción y Protección Vegetal, 23).

SOARES FILHO, C.V. Recomendações de espécies e variedades de Brachiaria para diferentes condições. In: SIMPÓSIO SOBRE MANEJO DA PASTAGEM, 11., Piracicaba, 1994. Anais... Piracicaba: FEALQ, 1994, p.25-48.

SOUZA, F.H.D. Panicum maximum in Brazil. In: LOCH, D. S.; FERGUSON, J.E. Forage seed production - vol. 2. Tropical and subtropical species. New York: CABI, 1999, p.363-370.

STUR, W.W. et al. Regional experience with Brachiaria: Asia, the south pacific and Australia. In: MILES et al. (Eds.). Brachiaria: biology, agronomy and improvement. Cali: CIAT, 1996. p.258-271.

THOMAS, D. et al. Andropogon gayanus var. bisquamulatus cv. Planaltina: principais características forrageiras. Pesquisa Agropecuária Brasileira, v.16, n.3, p.347-355, 1981. 
THOMAS, D.; ANDRADE, R.P. Desempenho agronômico de cinco gramíneas tropicais sob pastejo na região de cerrados. Pesquisa Agropecuária Brasileira, v.78, n.8, p.1047-1051, 1984.

VALLE, C.B. et al. Características das plantas forrageiras do gênero Brachiaria. In: SIMPÓSIO SOBRE MANEJO DE PASTAGENS, 17., 2000, Piracicaba. Anais... Piracicaba: FEALQ, 2000. p.65-108.

VALLENTINE, J.F. Grazing management. San Diego: Academic Press, 1990. 533p.

VILELA, L. et al. Calagem e adubação para pastagens na região do Cerrado. Planaltina: Embrapa Cerrados, 2000. 15p. (Circular Técnica, 37).

WERNER, J.C. Calagem para plantas forrageiras. In: SIMPÓSIO SOBRE MANEJO DE PASTAGENS, 8., 1986, Piracicaba. Anais... Piracicaba: FEALQ, 1986. p.191-198.

WERNER, J.C. Forrageiras. In: VAN RAIJ, B.; CANTARELA, H.; QUAGGIO, J.A et al. (Ed.). Recomendações de adubação e calagem para o Estado de São Paulo. $2^{a}$ Ed. Campinas: IAC, 1996. p.261-273. (Boletim Técnico, 100). 